\title{
Wanita dan Pengurusan Emosi Melalui Pengkisahan Maryam dalam al-Quran
}

\author{
Women and Emotional Competence from the Narrative of Maryam in al-Quran
}

NAJAH NADIAH AMRAN* \& HAZIYAH HUSSIN1

\begin{abstract}
Emotion has impact on individuals' ways of thinking and actions. It can be manifested physically and verbally. Studies indicate that male and female behaviours are dissimilars in emotional coping and reactions. Studies also underline the presence of internal and external factors, which related to stress and anxiety that can influence women's emotions. The failure of dealing with emotional burdens and battles can be devastating as it gives negative impacts to the individuals and community's quality of life and well-being. The aim of this article is to highlight the importance of emotional coping skill by examining the stories of women in the Quran.Verses of the Quran related to the stories of Maryam in the Quran and exegeses are compiled and analysed thematically. This article explores the personality of Maryam, the mother of Prophet Isa through the lens of life challenges and important elements and references in emotional coping. It classifies Maryam's life into four phases starting from her infancy to motherhood. Through those phases, Maryam underwent hardships and contested with the Israilites' tradition and challenges. This article concludes there are six important points in emotional coping skills that can empower women while dealing with life challenges and predicaments. They are: (i) stronghold of faith; (ii) consistency in religious ritual and submission; (iii) continuous efforts in purifying of soul; (iv) living in isolation or physically separating from toxic environment; ( $v$ ) seeking for external moral and physical supports; and (vi) sharpening essential life skills and strategies.
\end{abstract}

Keywords: emotion, emotional management skill, Maryam, Quranic stories, women empower

Emosi atau dalam bahasa Latin, emovere, menunjukkan maksud sesuatu bergerak jauh untuk keluar. Ia adalah bentuk gambaran perasaan dalaman seseorang yang diluahkan, dipamerkan atau dikeluarkan bagi menunjukkan rasa sedih, gembira, cinta, kecewa, semangat, marah dan benci. Menurut Fariza (2010), emosi ialah bangkitan perasaan dan rasa dalaman seseorang hasil tindak balas terhadap sesuatu keadaan, peristiwa atau pengalaman. Mok (2013) merujuk emosi kepada sesuatu perasaan dan pemikiran tersendiri di bawah keadaan psikologikal dan biologikal, serta ada kecenderungan yang berbeza-beza untuk bertindak. Emosi mempengaruhi gaya berfikir dan

\footnotetext{
${ }^{1}$ Najah Nadiah Amran* (corresponding author) Ph.D., senior lecturer at Research Centre for al-Quran and Sunnah Studies, Faculty of Islamic Studies, Universiti Kebangsaan Malaysia, 43600 BANGI, Selangor, Malaysia, email: najah@ukm.edu.my; Haziyah Hussin, Ph.D., senior lecturer at Research Centre for al-Quran and Sunnah, Faculty of Islamic Studies, Universiti Kebangsaan Malaysia, 43600 BANGI, Selangor, Malaysia, email: haziyah@ukm.edu.my.
} 
bertindak sehingga ia dapat dikenalpasti melalui tingkah laku (Asna 2014). Elemen emosi telah diberi perhatian lebih awal dalam pendidikan psikologi Islam (Hassan 1986). Menurut sarjana Islam seperti al-Ghazali pula, emosi dan hati manusia berkait rapat dengan pentauhidan kepada Allah sebagai pencipta. Oleh itu, emosi yang berpaksikan ketauhidan dapat mendorong dan mengawal tingkahlaku manusia dengan neraca baik dan buruk (Norsaleha \& Norhafiza 2016). Sebagai natijahnya manusia memperolehi ketenangan dan kesejahteraan dalam hidup. Antara sarjana barat yang mempopularkan perbahasan mengenai emosi ialah Goleman (1995) dalam karyanya Emotional Intelligence: Why it can Matter More than IQ. Beliau merujuk emosi sebagai perasaan, pemikiran, keadaan biologis dan psikologis serta kecenderungan tertentu yang mempengaruhi seseorang untuk melakukan sesuatu tindakan. Menurut Siddig (2012), Allah mengurniakan panduan dalam pembangunan insaniah sesuai dengan peranan manusia sebagai khalifah bagi memakmurkan alam. Terdapat ayat-ayat al-Quran yang secara umumnya memandu dalam kaedah berkomunikasi, kerja berpasukan, penyelesaian masalah, pembelajaran sepanjang hayat dan juga pembangunan diri. Menurut penulis lagi, al-Quran menekankan elemen keyakinan (akidah) dan kemahiran (skil) agar setiap Muslim menjadi individu yang baik lagi berperanan.

\section{Kepentingan Kemahiran Mengendalikan Emosi}

Tekanan hidup merujuk kepada keadaan jiwa yang mengalami ketegangan, pergolakan dan kegelisahan yang menggugat keupayaan seseorang untuk mengendali suatu situasi (Fariza 2010). Kegelisahan dan ketidakstabilan emosi terjadi akibat kegagalan seseorang mengawal sikap positif apabila berlaku sesuatu peristiwa dalam hidup (Hairunnaja 2005). Terdapat pelbagai faktor luaran yang mempengaruhi dan menjadi punca tekanan dan kegelisahan dalam kehidupan wanita. Antara faktor tersebut adalah perceraian, dibuang kerja, berkahwin, mendapat anak, kehilangan seseorang yang dikasihi, gangguan kesihatan, masalah kewangan, masalah dengan anak-anak, konflik dengan pasangan, berpindah rumah, kematian, berpindah tempat kerja, persekitaran dan faktor fizikal seperti mengandung. Selain itu terdapat juga faktor dalaman seperti motivasi dan jiwa yang lemah dan kegagalan seseorang bagi menyesuaikan diri dengan perubahan (Salasiah \& Adawiyah 2012). Kegagalan seseorang mengawal tekanan mental dan emosi boleh memberi impak terhadap kualiti dan kesejahteraan hidupnya secara holistik, termasuk menjejaskan kemampuannya berinteraksi dengan orang lain (Jabatan Perkhidmatan Awam 2018). Bahkan kegagalan mengawal emosi memberi kesan terhadap fisiologi, psikologi, tingkahlaku dan spiritual. Akibatnya terdapat individu yang sakit, murung, menyalahkan takdir Tuhan dan membunuh diri.

Nurhayati (2016) menjelaskan bahawa kemahiran mengendali atau pengurusan emosi mempamerkan kemampuan seseorang dalam mengawal emosi sehingga mampu meningkatkan perkembangan emosi dan intelek. Selain itu terdapat perbezaan antara pengurusan emosi antara golongan lelaki dan golongan wanita. Contohnya, wanita cenderung menguruskan emosi dengan cara meluahkan perasaan dan mendapatkan sokongan sosial ketika tekanan. Manakala golongan lelaki pula, menguruskan emosi dengan menzahirkan kekuatan fizikal dan perasaan marah. Oleh itu emosi seseorang hendaklah diuruskan dengan betul dan bijaksana (Mok 2013).

Menurut ahli psikologi Islam, pengurusan emosi adalah sama penting seperti pembangunan potensi fitrah yang lain iaitu melalui proses pertumbuhan dan perkembangan (Hassan 1986). Oleh itu emosi yang dibangunkan dan diuruskan dengan baik mempunyai keupayaan mengenali, memupuk dan membina kematangan yang akhirnya memberi kesan positif kepada kesejahteraan hidup dan tingkahlaku manusia. Dalam Islam, indikator seseorang yang mencapai tahap kecerdasan emosi adalah pada ketenangan dan kebahagiaan jiwa dengan pautan kepada ketentuan Allah SWT (Norsaleha \& Noor Hafizah 2016). Berbeza dengan konsep dan tahap pencapaian kecerdasan emosi 
barat yang hanya merujuk secara horizontal kepada keupayaan seseorang untuk mengetahui dan mengenalpasti emosi sendiri dan orang lain bagi memahami, menguasai, mengurus emosi tersebut supaya stabil serta memotivasi diri Najah Nadiah (2017).

Islam mengangkat martabat wanita dan memberi mereka hak dan taraf yang istimewa. Wanita ialah makhluk ciptaan Allah yang mempunyai kelebihan khusus untuk mengandung, melahirkan dan menyusukan anak. Wanita juga mempunyai sifat unik seperti penyayang, lembut dan tabah (Mek Wok 2014). Golongan wanita merupakan agen penting dalam masyarakat. Sumbangan mereka dilihat dalam pelbagai aspek khususnya dalam pembentukan ummah dan pembangunan negara (Mohd Roslan \& Nang Naemah n.d). Al-Quran memaparkan kisah mengenai tokoh dan personaliti wanita pilihan yang tertentu (Najah Nadiah et al. 2017). Melalui kajian terhadap kisah kehidupan mereka itu, didapati bahawa kaum wanita pada sepanjang zaman memainkan peranan yang besar bersama para Nabi AS. Selain itu, kisah tersebut juga memperlihatkan bahawa para wanita tersebut meninggalkan impak spiritual dan sosial yang besar kepada orang lain. Menurut Stowasser (1994), tokoh wanita yang hidup bersama Nabi Adam sehingga zaman Nabi Muhammad merupakan panduan hidup yang perlu diberikan perhatian. Bahkan mereka terlibat secara langsung sama ada di peringkat pentadbiran negara sehingga pengurusan domestik dalam komuniti dan keluarga. Paparan kisah mereka dalam al-Quran membuktikan pergerakan sosial dan sumbangan wanita tidak terbatas dalam sempadan rumahtangga sahaja. Malah masyarakat memerlukan peranan wanita dalam bidang-bidang kehidupan dan alam pekerjaan yang bersesuaian (Najah Nadiah et al. 2017).

\section{Identiti dan Personaliti Maryam dalam Al-Quran}

Maryam ialah satu-satunya wanita yang disebut namanya dalam al-Quran malah Allah mengabadikan namanya sebagai nama surah. Nama Maryam dinyatakan sebanyak 34 kali dalam 31 ayat al-Quran (al-Khalidi 2006). Sebanyak 23 kali sebutan nama Maryam digandingkan dengan kata nama lain bagi menjelaskan identitinya sebagai ibu kepada Nabi Isa AS. Contohnya: (a) "Ibn Maryam"; (b) "Isa ibn Maryam"; (c) "al-Masih Isa ibn Maryam"; dan (e) "al-Masih ibn Maryam". Manakala di sebelas ayat yang nama Maryam lain disebut bersendirian sebagai "Maryam" dan ibu kepada Nabi Isa AS iaitu "ibn Maryam wa ummuhu". Pengulangan ini menonjolkan kemuliaan personaliti dan darjat Maryam di sisi Allah SWT. Antara ciri-ciri kekuatan personaliti beliau ialah kecerdasan dalam mengendali emosi dalam mendepani cacian dan hinaan oleh Bani Israil yang menuduhnya berbuat jahat selain mempertikaikan anak yang dikandungnya. Pengalaman Maryam dalam mengurus tekanan dan kemahirannya dalam mengawal emosi wajar diketengahkan agar diteladani sejajar dengan tujuan pembentangan qasas dalam al-Quran.

\section{Latar Belakang Keluarga Maryam}

Maryam berketurunan keluarga Imran, iaitu sebuah keluarga mulia pilihan Allah daripada kalangan Bani Israil. Firman Allah dalam surah Ali 'Imran: 33-34 yang bermaksud: "Sesungguhnya Allah telah memilih Adam, Nuh, keluarga Ibrahim dan keluarga 'Imran melebihi segala umat (yang ada pada zaman masing-masing). (Sebagai) satu keturunan yang setengahnya berasal daripada setengahnya yang lain". Keutamaan dan pilihan Allah kepada keluarga ini di atas faktor silsilah keturunan Nabi Ibrahim AS (Al-Zuhayli 2007) dan juga faktor moraliti agama, ketaatan dan hidayah (Al-Sha'rawi 2007). Bapa Maryam iaitu `Imran merupakan lelaki soleh dan ibunya Hannah wanita solehah yang sangat taat beribadah kepada Allah. Mereka berdua sentiasa setia mengabdikan diri di Baitul Maqdis (Najah Nadiah et al. 2017). Ciri-ciri inilah yang melayakkan keluarga Imran menjadi pilihan Allah 
(Said Hawwa 2003). Hannah dan Imran dikatakan tidak dikurniakan anak setelah lama berkahwin. Lalu mereka berdoa memohon kepada Allah dengan sabar dan penuh ketaatan (Al-Zuhayli 2007).

Apabila Hannah hamil beliau bernazar menyerahkan anak untuk berkhidmat di Baitul Maqdis. Firman Allah dalam surah Ali-'Imran ayat 35 yang bermaksud: "(Ingatlah) ketika isteri Imran berkata: "Tuhanku! Sesungguhnya aku nazarkan kepada-Mu apa yang ada dalam kandunganku menjadi hamba yang mengabdi (kepada-Mu), maka terimalah nazarku. Sesungguhnya Engkaulah Yang Maha Mendengar lagi Maha Mengetahui". Menurut Abdul Hayei (2011), frasa "ma fi batni" (dalam ayat 35 di atas) mencerminkan ketulusan dan ketinggian ketaatan isteri Imran kerana nazar itu ditekadkan tanpa mengetahui jantina anak tersebut. Namun dapat difahami bahawa jantina anak yang diharapkan ialah seorang lelaki yang melayakkannya sesuai untuk berkhidmat di Baitul Maqdis. Kata "muharrara" pula bermaksud orang yang dibebaskan dan diserahkan kepada Allah semata-mata untuk beribadat dan berkhidmat kepadaNya (Said Hawwa 2003), tidak dicemari dengan hal-hal duniawi. Al-Sha'rawi (2007) mengupas rahsia di sebalik munajat seorang ibu dan motifnya bahawa Hannah hidup dalam lingkungan masyarakat yang berbangga dengan anak-anak lelaki dan ingin mengatur gerak hidup anak-anak sehingga menjadi kebanggaan keluarga. Namun, keinginan Imran dan Hannah berbeza dari tradisi tersebut. Mereka bertekad agar anak yang bakal lahir nanti itu dibebaskan untuk berkhidmat kepada Baitul Maqdis.

\section{Fasa-Fasa Mencabar dalam Kehidupan Maryam}

Maryam telah diuji dengan pelbagai cabaran dan ujian oleh Allah sepanjang kehidupannya. Fasa kehidupan Maryam yang mencabar diklasifikasikan kepada empat fasa berikut:

\section{Fasa Satu: Membesar dalam Lingkungan Biarawan Lelaki}

Perjalanan hidup Maryam sejak dari kecil menunjukkan bahawa beliau meninggalkan zon keluarga yang selesa demi memberikan bakti kepada Allah bagi memenuhi nazar ibubapanya. Sepanjang itu, Maryam dan ibunya terpisah. Jarak yang jauh menyukarkan Maryam untuk menemui ibunya dengan kerap. Bagi seorang anak, keinginan untuk berada dalam pelukan keluarga lebih-lebih lagi ibubapa sendiri sangat kuat. Setelah beberapa lama berada di sana, Maryam mendapat khabar dukacita bahawa ibunya telah meninggal dunia. Namun jaminan dan penjagaan daripada Allah dan juga pengawasan Nabi Zakaria a.s. menjadikan beliau meneruskan hasrat ibubapanya dan kekal berada di Baitul Maqdis. Selain itu, beliau juga perlu berhadapan dengan cabaran sosio-budaya dan agama kerana nazar ibunya itu seperti melawan tradisi yang menjadi amalan agama dan pegangan majoriti umat Bani Israel pada ketika itu (Najah Nadiah et al. 2017). Maryam terpaksa menelan tentangan para biarawan dan agamawan yang tidak meredai kehadiran wanita di tempat suci agama Yahudi. Isu gender adalah perkara yang dominan di sisi mereka. Secara khususnya Maryam berkeseorangan bekerja di alam dan ruang yang didominasi oleh kaum lelaki (Najah Nadiah et al. 2017). Kajian mendapati apabila seseorang itu ditempatkan dalam situasi sukar dan mencabar, dia akan bertindakbalas dan berkembang menjadi insan hebat apabila berjaya mengatasinya (Brown 2008).

\section{Fasa Kedua: Kehamilan Tanpa Bersuami}

Urusan kehamilannya ini adalah urusan Allah dan berlaku dengan keizinan-Nya jua tanpa memenuhi sebab musabab. Inilah salah satu ciri keutamaan Maryam berbanding wanita-wanita lain iaitu wanita suci yang hamil tanpa berkahwin. Firman Allah Taala dalam surah Ali Imran: 45-47 yang bermaksud: 
(Ingatlah) ketika malaikat berkata: Wahai Maryam! Bahawasanya Allah memberikan khabar yang menggembirakanmu, dengan (mengurniakan seorang anak yang engkau akan kandungkan semata-mata dengan) Kalimah daripada Allah, nama anak itu: alMasih Isa Ibn Maryam, seorang yang terkemuka di dunia dan di akhirat, dan ia juga dari orang-orang yang didampingkan (diberi kemuliaan di sisi Allah). Dan dia akan berkata-kata kepada orang ramai semasa ia masih kecil dalam buaian, dan semasa dia dewasa, dan dia adalah dari orang yang salih. Maryam berkata: Wahai Tuhanku! Bagaimanakah aku akan beroleh seorang anak, padahal aku tidak pernah disentuh oleh seorang lelaki pun? Allah berfirman: Demikian keadaannya, Allah menjadikan apa yang dikehendaki-Nya; apabila Dia berkehendak melaksanakan sesuatu perkara, maka Dia hanyalah berfirman kepadanya: Jadilah engkau, lalu menjadilah ia.

Peristiwa dalam ayat di atas turut diulas oleh Said Hawwa (2003) sebagai tanda karamah Maryam. Fakta sains menetapkan kehamilan wanita itu berlaku disebabkan bertemunya sel telur perempuan dengan sperma lelaki. Belum pernah berlaku dalam sejarah manusia sehingga kini kejadian yang mengejutkan seperti mana yang berlaku kepada Maryam yang mengandung hasil ditiup ruh daripada Allah ke dalam rahimnya. Ujian kehamilan tanpa suami benar-benar menguji keupayaan Maryam untuk menguruskan emosinya. Beliau meletakkan segala keyakinan kepada Allah walaupun menerima cacian dan hinaan yang bertubi-tubi dari Bani Israil. Ketenangan hati yang dikecapi oleh Maryam ketika menerima ketentuan Allah menunjukkan kecerdasan emosi yang tinggi. Malah sifat kental dapat dilihat bagaimana dia mendepani kejutan demi kejutan yang menimpa dirinya. Dia tidak kecewa dan menerima ketentuan yang ditetapkan Allah kepadanya walaupun dia menerima tekanan yang sangat tinggi daripada Bani Israil. Menurut Alifah (2012) individu yang lemah dan tiada keupayaan dalam mengawal emosinya akan terpaksa berhadapan dengan tekanan manakala individu yang bijak menguruskan emosi akan dapat menghindari tekanan hidup dan kekecewaan.

Maryam telah diperjelaskan sejak dari awal bahawa anak tersebut adalah seorang yang suci yang dianugerahkan Allah Taala sebagai rahmat, diberi nama Isa dan digelar al-Masih, serta akan menjadi nabi dan tokoh terkemuka dan agung di dunia dan menjadi golongan yang dekat di sisi Allah di akhirat. Anak tersebut juga mempunyai beberapa mukjizat selain seorang yang sempurna dari sudut ketakwaan dan kesolehan (Al-Sabuni 2005). Khabar kehamilan itu dianggap sebagai bushra iaitu berita gembira dengan melihat kepada kesan terhadap agama suatu hari kelak. Bagi menyuburkan dan mengukuhkan keimanan Maryam dengan takdir itu, Allah menegaskan dengan ayat bermaksud: "hal itu mudah bagi-Ku dan Kami hendak menjadikannya sebagai sebagai satu tanda kekuasaan Kami untuk manusia, dan sebagai satu rahmat dari Kami. Dan hal itu adalah satu perkara yang telah ditetapkan berlaku.".

\section{Fasa Ketiga: Pengasingan dan Bersendirian Semasa Melahirkan Isa AS}

Setelah mengandung, Maryam mengasingkan diri ke tempat jauh, iaitu Bayt Lahm yang terletak sebelah timur, iaitu tujuh batu dari Baitul Maqdis. Hal ini kerana perubahan fizikal dengan perut semakin membesar bakal mengundang pertanyaan banyak orang sekaligus membicarakan dirinya (Ibn Kathir 2005). Firman Allah Taala yang menggambarkan fasa pengasingan dan keadaan Maryam bersendirian terdapat dalam surah Maryam: 22-24, maksudnya: 
Maka Maryam mengandungnya, lalu ia menyisihkan diri dengan kandungannya itu ke tempat yang jauh. Maka rasa sakit akan melahirkan anak memaksa dia (bersandar) pada pangkal pohon kurma, Dia berkata: "Aduhai, Alangkah baiknya aku mati sebelum ini, dan aku menjadi barang yang tidak berarti, lagi dilupakan".

Menurut Dini A.P. Prapto, H. Fuad Nashori dan Rumiani (2015), rasa gelisah dan cemas adalah suatu lumrah semasa hamil kerana wanita yang hamil mengalami suatu proses penyesuaian yang wajar terhadap perubahan fizikal dan psikologi. Perubahan ini terjadi akibat perubahan hormon yang akan mempermudah janin untuk tumbuh dan berkembang sehingga ia dilahirkan. Demikian juga semasa menghadapi proses bersalin, wanita mudah mengalami tekanan dan ketakutan apatah lagi sekiranya kehamilan dan kelahiran itu adalah kali pertama. Tekanan tersebut jika tidak dikawal, boleh memberi kesan buruk kepada fizikal dan jiwa ibu serta memiliki risiko 50 peratus mendapat anak yang cacat. Ia juga boleh menjejaskan proses bersalin kerana saat adalah kemuncak tekanan yang dihadapi oleh ibu yang hamil (Riza Wahyunia \& Deswitaa 2013).

Ibu yang hampir bersalin memerlukan seseorang di sisinya sama ada suami atau keluarga terdekat bagi memberi panduan serta menenangkan dan memberi sokongan. Dalam kisah Mayam, kesakitan secara fizikal dan psikologi itu memaksa Maryam bersandar pada pangkal pohon kurma bagi mencari kekuatan. Maryam berkata: "Aduhai! Alangkah baiknya aku mati sebelum ini, dan aku menjadi barang yang tidak bererti lagi dilupakan." (Qutb 2004). Luahan ini terbit kerana rasa malu dan sedih kerana dia melahirkan anak tanpa ada suami bahkan menyedari bahawa selepas ini dia bakal mendapat ujian dan cubaan dengan anak yang dilahirkannya ini. Masyarakat pula akan sukar mempercayai khabar yang disampaikannya sekalipun mereka mengenalinya sebagai wanita yang taat dan tekun beribadah. Mereka akan menuduhnya telah berubah menjadi wanita pelacur dan penzina (Ibn Kathir 2005).

Semasa Maryam hampir putus harapannya, Allah mengutuskan Jibril a.s. bagi mengurangkan kesedihan dengan menyampaikan berita gembira dan berpesan dengan tindakan dan respon yang harus diambil Maryam kelak.

Maka Jibril menyerunya dari tempat yang rendah: "Janganlah kamu bersedih hati. Sesungguhnya Tuhanmu telah menjadikan anak sungai di bawahmu. dan goyanglah pangkal pohon kurma itu ke arahmu, nescaya pohon itu akan menggugurkan buah kurma yang masak kepadamu, Maka makan, minum dan bersenang hatilah kamu. Jika kamu melihat seorang manusia, Maka Katakanlah: "Sesungguhnya aku telah bernazar berpuasa untuk Tuhan yang Maha pemurah, Maka aku tidak akan berbicara dengan seorang manusia pun pada hari ini" (Surah Maryam: 25-26).

Jibril menjalankan tugas dengan perintah dan bimbingan Allah serta pengawasan-Nya sehingga Isa a.s. dilahirkan dengan selamat. Selepas bersalin, Maryam diperintahkan supaya berpuasa, jangan bercakap dengan sesiapa, menyerahkan segala urusan kepada Allah (Ibn Kathir 2005). Peristiwa ini menunjukkan bahawa Maryam menghadapi tekanan emosi yang sangat berat ketika hendak melahirkan.

\section{Fasa Keempat: Pulang Ke Pangkuan Masyarakat Sebagai Ibu Seorang Nabi}

Seterusnya Maryam membawa pulang bayinya kerana patuh kepada arahan Allah. Terdapat pelbagai reaksi negatif masyarakat tatkala melihat Maryam pulang membawa seorang bayi. Ada yang menangis dan sedih. Ada juga mereka yang mencela serta menuduh Maryam melakukan zina. Mereka juga mempersoalkan kewajaran perbuatan Maryam itu sedangkan dia berasal dari keluarga yang 
baik agamanya dan soleh. Bahkan kesolehan dan ibadat Maryam disifatkan menyerupai Harun a.s. turut terpersoalkan (Ibn Kathir 2005; al-Sabuni 2005). Inilah fasa cabaran yang paling kemuncak dalam hidup Maryam. Maksud firman Allah dalam surah Maryam, ayat 27-30:

Maka Maryam membawa anak itu kepada kaumnya dengan menggendongnya. Kaumnya berkata: "Hai Maryam, Sesungguhnya kamu telah melakukan sesuatu yang amat mungkar. Hai saudara perempuan Harun, ayahmu sekali-kali bukanlah seorang yang jahat dan ibumu sekali-kali bukanlah seorang penzina".

Maryam tidak mengatakan apa-apa kecuali menunjuk bayinya kerana dialah satu-satunya saksi akan kesucian dan kebebasan Maryam serta kebenaran imannya. Dengan kekuasaan Allah, bayi itu dapat berbicara. Allah berfirman: Isa berkata: "Sesungguhnya aku ini hamba Allah, Dia memberiku al-Kitab (Injil) dan Dia menjadikan aku seorang Nabi, dan Dia menjadikan aku seorang yang diberkati di mana saja aku berada, dan Dia memerintahkan kepadaku (mendirikan) solat dan (menunaikan) zakat selama aku hidup; dan berbakti kepada ibuku, dan Dia tidak menjadikan aku seorang yang sombong lagi celaka. Dan kesejahteraan semoga dilimpahkan kepadaku, pada hari aku dilahirkan, pada hari aku meninggal dan pada hari aku dibangkitkan hidup kembali." (Maryam: 30-33).

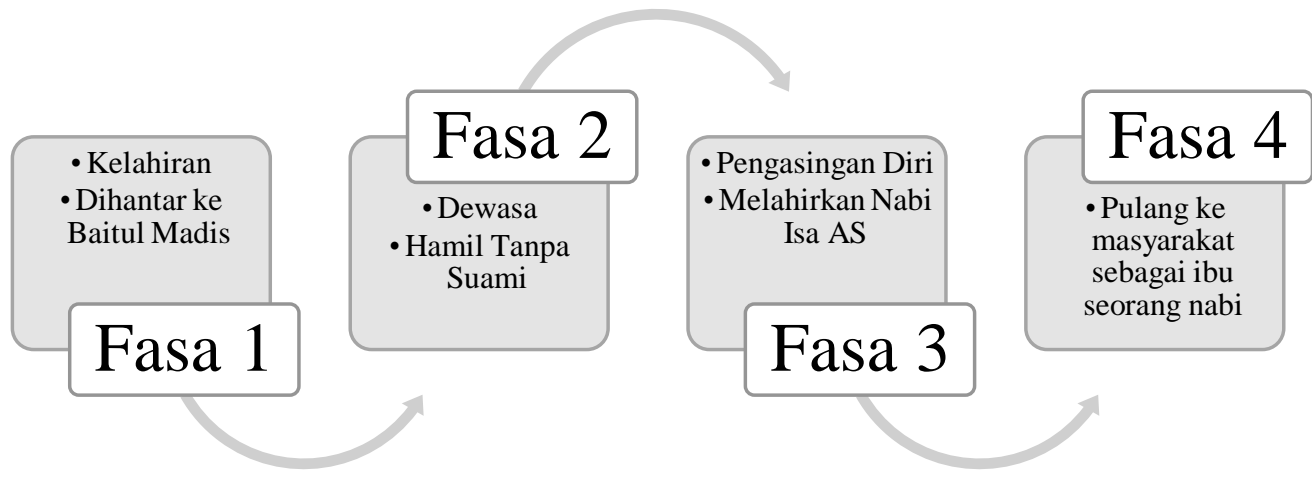

Gambarajah 1: Ringkasan Empat Fasa Kehidupan Maryam, Ibu Nabi Isa AS

(Sumber: Najah Nadiah \& Haziyah 2019)

\section{Pengurusan Emosi dari Pengkisahan Maryam}

Menurut Sayyid Qutb (2004), senario yang melatari kisah kehidupan Maryam semasa dipelihara oleh Nabi Zakaria kehamilan dan kelahiran Isa diwarnai dengan emosi. Meskipun begitu, ia didominasi oleh rahmat, limpahan kasih sayang dan reda Allah. Kekentalan jiwa Maryam terserlah melalui peristiwa sejak dari kecil, membesar di Baitul Maqdis, melahirkan dalam keadaan bersendirian, tanpa ada suami atau siapa pun yang menemani, keengganan Bani Israil menerima kelahiran Isa a.s. dan juga tuduhan zina.

Terdapat enam panduan pengurusan emosi yang ditunjukkan oleh Maryam semasa hayatnya iaitu: (a) kekuatan iman: kebergantungan kepada Allah dan Qadak dan Qadar-Nya; (b) ibadat: memperbanyakkan amalan anggota dan lisan bagi menampung kekuatan dalaman; (c) tazkiyyah; (d) uzlah; (e) mendapatkan sokongan luar; dan (f) kemahiran dan tindakan berstrategi. Antara petunjuk yang dipedomani dari reaksi-reaksi Maryam semasa berhadapan cabaran adalah: 
(a) Kepentingan pergantungan kepada Allah dan kepentingan dipimpin oleh rasa ubudiyyah: kebergantungan seorang mukmin kepada Allah menjadi bukti keutuhan iman dan keyakinannya kepada janji Allah. Persoalan yang sering dilontarkan oleh seseorang yang tertekan seperti ungkapan "kenapa aku, bukan orang lain? Apa salahku?" adalah perkara lumrah. Menurut al-Sha'rawi (2007), Maryam telah bertanya "Bagaimanakah aku akan beroleh anak lelaki, sedang aku tidak pernah disentuh oleh seorang lelaki pun, dan aku bukan perempuan jahat?" (surah Maryam: 20). Namun nilai ubudiyyah telah menyedarkan Maryam mengenai kudrat Allah. Allah berfirman dalam surah Ali 'Imran: 47: "Demikian keadaannya, Allah menjadikan apa yang dikehendaki-Nya; apabila Dia berkehendak melaksanakan sesuatu perkara, maka Dia hanyalah berfirman kepadanya: Jadilah engkau, lalu menjadilah ia".

(b) Melazimi dan memperbanyakkan solat dan zikir: Allah titipkan arahan kepada Maryam: "Wahai Maryam! Taatlah kepada Tuhanmu, dan sujudlah serta rukuklah (mengerjakan sembahyang) bersama-sama orang-orang yang rukuk" (Ali 'Imran: 43). Menurut Ibn Kathir (2005), solat adalah faktor terbesar kepada ketabahan dan keteguhan individu dalam menghadapi sesuatu perkara. Kaedah yang sama disarankan oleh ulama seperti al-Ghazali bagi mengatasi tekanan iaitu mujahadah melawan nafsu, menginsafi sifat kehidupan di dunia ini yang sementara, mengingati mati, memperbanyakkan zikir dan melihat individu yang lebih rendah dalam hal-hal keduniaan serta meningkatkan rasa syukur terhadap nikmat Allah SWT (Salasiah Hanin \& 'Adawiyah 2012).

(c) Penerusan tazkiyyah al-nafs: penyucian jiwa menekankan aspek pendidikan kerohanian dalam jiwa manusia dengan kaedah latihan keagamaan atau ibadat. Ia adalah satu kaedah kecerdasan spiritual dan penerapan akhlak melalui proses penghapusan akhlak mazmumah dan menggantikannya dengan akhlak mahmudah. Ia bertujuan untuk memurnikan jiwa dengan memahami konflik dalam diri dan serta mendidik hati (Abu Darda' et al. 2017).

(d) Beruzlah menjauhi persekitaran dan punca tekanan: tekanan berlaku adalah berpunca daripada individu itu sendiri atau melibatkan kelompok manusia (Siti Noorshafenas \& Ahmad Yunus 2016). Malah tuntutan persekitaran yang melampaui keupayaan diri dan kegagalan individu menyesuaikan tuntutan tersebut akan menyebabkan individu rasa tidak puas hati dalam memenuhi keperluannya sendiri boleh mendorong berlakunya tekanan (Salasiah Hanin \& 'Adawiyah 2012). Kisah Maryam ini menunjukkan hebatnya percaturan Allah SWT apabila mengarahkan Maryam mengasingkan diri secara fizikal sepanjang kehamilannya (Surah Maryam: 22-26). Sekiranya, Maryam tidak keluar dari kelompok Bani Israil nescaya beliau akan berhadapan dengan kesukaran yang tidak dapat ditanggung secara fizikal dan emosi.

(e) Mendapatkan sokongan luar: semasa mengasingkan diri, Maryam mengalami runtunan emosi sehingga hampir putus asa. Namun Allah menyediakan sokongan luar iaitu: (i) sokongan spiritual melalui pengutusan Malaikat Jibrail untuk memperteguhkan hati Maryam bahawa anak yang lahir itu bakal membawa rahmat; dan (ii) sokongan fizikal dengan menyediakan pohon tamar berbuah dan air sungai mengalir bagi menambah tenaga.

(f) Mempertajamkan kemahiran dan membuat tindakan berstartegi: seperti yang dijelaskan, Maryam dipesan agar menyatakan bahawa beliau bernazar untuk tidak bercakap dengan sesiapa. Di sisi Bani Israil, nazar adalah suatu kewajipan agama yang tidak akan dipersoalkan. 
Beliau tidak berkomunikasi secara lisan kerana tohmahan yang dilemparkan melebihi kemampuan fizikal untuk membalas. Namun Allah mengilhamkan kepadanya agar menunjukkan anak kepada mereka seolah berkata; tanyalah anak ini kerana aku tidak dapat bercakap kerana bernazar untuk diam. Diam merupakan satu bentuk reaksi dan komunikasi non-verbal. Akhirnya, Bani Israil tercengang dan tersungkur sujud apabila bayi yang dibawa Maryam itu berkata: "Sesungguhnya aku ini hamba Allah, Dia memberiku al-Kitab (Injil) dan Dia menjadikan aku seorang Nabi." (Surah Maryam: 30).
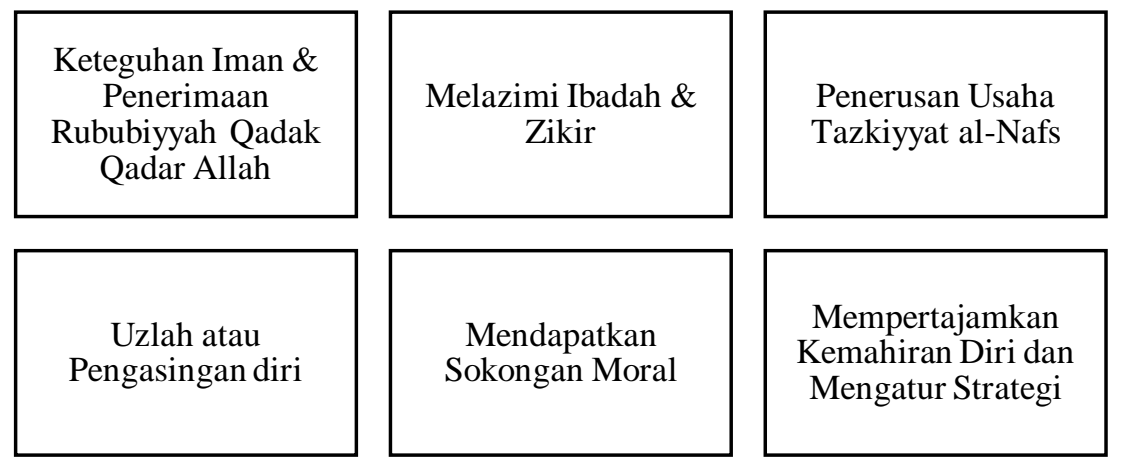

Gambarajah 2: Panduan Pengendalian Emosi Maryam, Ibu Nabi Isa AS (Sumber: Najah Nadiah \& Haziyah 2019)

Kekentalan jiwa Maryam terserlah melalui keupayaannya mendepani peristiwa kehidupan sejak dari awal iaitu pada saat dihantar ke Baitul Maqdis bagi menunaikan nazar ibubapanya dan hidup dalam kalangan kaum lelaki Bani Israil. Seterusnya Maryam membesar dan dewasa. Beliau mengalami fasa kehidupan yang lebih mencabar selepas itu iaitu fasa kehamilan, melahirkan bayi dalam keadaan bersendirian, tanpa ada suami atau siapa pun yang menemani. Sekembalinya Maryam selepas bersalin, Bani Israil enggan menerima kelahiran Isa AS bahkan mereka membuat tuduhan dan tohmahan zina ke atasnya. Meskipun begitu, semua ujian ini ditanganinya dengan keyakinan sepenuhnya kepada Allah dan bantuan-Nya. Kisah ini sangat menarik untuk ditelusuri berdasarkan kepada perkhabaran wahyu, terutamanya dalam konteks membicarakan perihal keesaan Allah, kekuasaan dan kehendak-Nya serta kewajiban beriman dengan perkara-perkara ghaib. Penghayatan terhadap kisah seperti ini membolehkan kita memperolehi beberapa panduan psikologi dan pembangunan latihan kemahiran diri dalam berdepan dengan musibah sepertimana didikan Allah kepada Maryam. Terdapat enam elemen utama dalam terapi dan pengurusan emosi Maryam yang berguna bagi pemerdayaan wanita pada masakini bagi menangani tekanan, cabaran kehidupan atau mendapatkan solusi iaitu wanita perlu: (a) melaksanakan usaha secara maksima bagi mendapatkan kekuatan iman dan rasa kebergantungan yang total kepada Allah dan Qadak dan Qadar-Nya; (b) melazimi ibadat ritual dengan memperbanyakkan amalan anggota badan dan lisan bagi menampung kekuatan dalaman; seterusnya wanita juga digalakkan (c) melakukan usaha-usaha tazkiyyah al-nafs dan; berkesanggupan untuk (d) uzlah iaitu berpindah atau pengasingan diri secara fizikal dari kondisi negatif; selain itu, mereka juga perlu (e) mendapatkan sokongan luar yang dapat memandu hati dan menenangkan fikiran; wanita juga dikehendaki (f) menambahkan ilmu pengetahuan dan latihan bagi mempertajamkan kemahiran dan memilih tindakan terbaik. 


\section{Acknowledgement}

This article is part of research output from the scheme of Geran Galakan Penyelidik Muda, Universiti Kebangsaan Malaysia, GGPM-2016-087 Pembinaan Model Kemahiran Insaniah Belia Wanita Berpandukan al-Quran.

\section{References}

Abdul Hayei Abdul Sukor. 2011. Tafsir Pedoman Muttaqin. Juz 3. Putrajaya: Jabatan Kemajuan Islam Malaysia.

Abu Darda' Mohamad, Salasiah Hanin Hamjah, Ahmad Irdha Mokhtar \& Mohamad Zulkifli Abdul Ghani. 2017. Tazkiyat al-nafs dalam kerangka maqasid al-shari'ah. Jurnal Al-Hikmah 9 (2): 87-98.

Alifah Saring. 2012. Hubungan kecerdasan emosi dan gaya pembelajaran dengan prestasi akademik. Tesis Sarjana. Universiti Tun Hussein Onn Malaysia.

Asna Adriani. 2014. Kecerdasan emosional (emotional quotient) dalam peningkatan prestasi belajar. Edukasi Jurnal Pendidikan Islam 2(1): 459-472.

Brown, Mike. 2008. Comfort zone: model or metaphor? Australian Journal of Outdoor Education 12(1): 3-12.

Dini A.P. Prapto, H. Fuad Nashori \& Rumiani. 2015. Terapi tadabbur al-Qur'an untuk mengurangi kecemasan menghadapi persalinan pertama. Jurnal Intervensi Psikologi 7(2): 131-142.

Fariza Md. Sham. 2010. Pendekatan psikologi dakwah dalam menangani masalah tekanan emosi remaja: fokus kepada memberi perhatian dan kasih sayang. Jurnal Al-Hikmah 2: 107-118.

Goleman, Daniel. 1995. Emotional Intelligence. USA: Bantam Books.

Hasan Langgulung. 1986. Manusia dan Pendidikan: Suatu Analisa Psikologi dan Pendidikan. Jakarta: Pustaka al-Husna.

Hairunnaja Najmuddin. 2005. Membimbing Remaja Memilih Pendidikan \& Kerjaya. Pahang: PTS Professional Publishing.

Ibn Kathir, Abu al-Fida' Ismail. 2005. Tafsir al-Qur'an al-Azim. Juz 2. Beirut: Dar al-Fikr.

Jabatan Perkhidmatan Awam. 2018. Kecelaruan mental. (online) www.jpa.gov.my/index.php?option=com_content.

Mek Wok Mahmud. 2014. Hak-hak, Penglibatan Wanita Islam. Selangor: Persatuan Ulama' Malaysia.

Mohd Roslan Mohd. Nor \& Nang Naemah Nik Dahalan. n.d. Wanita dalam Pendidikan Tinggi di Malaysia. Kuala Lumpur: Akademi Pengajian Islam Universiti Malaya.

Mok Soon Sang. 2013. Perkembangan Kanak-Kanak. Cet. 3. Selangor: Penerbitan Multimedia Sdn. Bhd.

Najah Nadiah Amran, Fazilah Idris, Haziyah Hussin, 'Adawiyah Ismail, Latifah Abdul Majid, Rozita Ibrahim \& Wan Nur 'Ashiqin Wan Mohamad 2017. Pengabdian sosial keluarga Imran. In. Isuisu Kontemporari dalam Zakat, Wakaf dan Filantrofi Islam, pp. 458-467. Shah Alam: Akademi Pengajian Islam Kontemporari UiTM.

Najah Nadiah Amran. 2017. Kecerdasan personal dua wanita pilihan dalam al-Quran. Conference paper. International Conference on Muslim Society and Thought (IC-MUST) 2017. Surabaya, Indonesia, 3-5 Oktober.

Norsaleha \& Noor Hafizah. 2016. Konsep kecerdasan emosi dalam Islam. Seminar Antarabangsa Akidah, Dakwah dan Syariah. May 10th.

Nurhayati. 2016. Klasifikasi dan pengurusan emosi remaja daripada ibu bapa yang bercerai. Disertasi Sarjana. Universiti Kebangsaan Malaysia. 
Qutb, Sayyid. 2004. Fi Zilal al-Qur'an. Juz 4. Cet. 34. Kaherah: Dar al-Syuruq.

Riza Wahyunia, Deswitaa. 2013. Pengaruh terapi murotal terhadap tingkat kecemasan menghadapi persalinan pada ibu hamil di wilayah kerja Puskesmas Andalas. Ners Jurnal Keperawatan 9(2): 111-122.

al-Sabuni, Muhammad Ali. 2005. Al-Tafsir al-Wadih al-Muyassar. Cet. 6. Beirut: al-Maktabah alAsriyyah.

Said Hawwa. 2003. Al-Asas fi al-Tafsir. Jil. 2 \& 6. Cet. 6. Kaherah: Dar al-Salam.

Salasiah Hanin Hamjah \& 'Adawiyah Ismail. 2012. Kaedah mengatasi tekanan dalam kalangan wanita bekerjaya dari perspektif al-Ghazali. Jurnal al-Hikmah 4: 64-75.

Siddig Ahmad. 2012. Generic skills from Quranic perspective. International Journal of Islamic Thought 1 (1): 43-53.

Siti Noorshafenas Safe \& Ahmad Yunus Mohd Nor. 2016. Pengurusan stress menurut al-Quran dan Hadith. Jurnal Al-Hikmah 8(1): 3-18.

Stowasser, Barbara Freyer. 1994. Women in the Qur'an, Tradition and Interpretation. New York: Oxford University Press.

al-Sha'rawi, Muhammad Mutawalli. 2007. Isa dan Maryam. Terj. H. Imam Firdaus. Kuala Lumpur: Jasmin Enterprise.

al-Zuhayli, Wahbah. 2007. Tafsir al-Munir (terjemahan). Juz 3. Petaling Jaya: Persatuan Ulama Malaysia \& Intel Multimedia and Publication. 